\title{
The apical ectodermal ridge regulates Hox -7 and Hox-8 gene expression in developing chick limb buds
}

\author{
Benoît Robert, ${ }^{1,4}$ Gary Lyons,, ${ }^{1,5}$ B. Kay Simandl, ${ }^{2}$ Atsushi Kuroiwa ${ }^{3}$ and Margaret Buckingham ${ }^{1}$ \\ ${ }^{1}$ Departement de Biologie Moléculaire and URA 1148 du Centre Nationale de la Recherche Scientifique, Institut Pasteur, \\ 75724 Paris Cedex 15, France; ${ }^{2}$ Department of Anatomy, University of Wisconsin, Madison, Wisconsin 53706 USA; \\ ${ }^{3}$ Department of Cell Biology, Research Institute for Tuberculosis and Cancer, Tohoku University, Sendai 980, Japan
}

\begin{abstract}
We show that expression of the two related chicken homeo box genes, $\mathrm{Hox}-7$ and $\mathrm{Hox}-8$, which is widespread in the lateral mesoderm at early stages, becomes restricted to the mesoderm underlying the apical ectodermal ridge as limbs develop. Expression in the limb bud mesoderm is not maintained in the limbless mutant, which does not form an apical ridge. The mutant can be rescued by grafting normal ectoderm to the limb field. This leads to expression of the two homeo box genes in the mesoderm under the induced ridge. Phenocopies of eudiplopodia, which form an ectopic ridge on the limb bud, express the two genes under both ridges. When a quail ridge is grafted over nonexpressing mesoderm, a new site of expression is induced. Therefore, Hox -7 and $H o x-8$ depend on a functional ridge for their continued expression in the limb bud and can be induced by it.
\end{abstract}

[Key Words: Homeo box genes; ectodermal-mesodermal interactions; limb; chick developmental mutations; in situ hybridization]

Received August 15, 1991; revised version accepted October 15, 1991

Limbs in the chick develop through a series of epithelial-mesenchymal interactions (for review, see Zwilling 1961; Saunders 1977). The same has been demonstrated for amphibians (Harrison 1931; Tschumi 1957) and probably holds true for all vertebrate tetrapods. Mesoderm from the limb field in the somatopleure causes the formation, in competent ectoderm, of a pseudostratified columnar epithelium at the tip of the forming bud, the apical ectodermal ridge (Kieny 1960; Dhouailly and Kieny 1972; Carrington and Fallon 1984; Saunders and Reuss 1974). The apical ridge is thought to be induced and maintained by a diffusible signal from the limb field mesoderm (Zwilling 1961). This apical ridge, in turn, is required for the outgrowth of the mesoderm and for the determination of the limb structures along the proximodistal axis. This is best demonstrated by manipulations of the ridge: If excised, only the proximal parts of the limb already determined at the time of excision will develop, leading to a truncated limb (Saunders 1948; Summerbell 1974; Rowe and Fallon 1982). On the other hand, grafting an extra apical ridge onto the limb bud leads to the duplication of the outgrowth and the formation of two sets of distal structures (Zwilling 1956; Saunders et al. 1976).

\footnotetext{
${ }^{4}$ Corresponding author.

${ }^{5}$ Present address: Department of Anatomy, University of Wisconsin, Madison, Wisconsin 53706 USA.
}

These experiments are substantiated by the analysis of mutants affected in limb development. Two such mutants in the chick are of special relevance to the morphogenetic role of the ridge, limbless and eudiplopodia. Both of these mutations are recessive. The limbless mutant is unable to form a ridge and, as a result, develops neither wing nor leg structures (Prahlad et al. 1979). At early stages, however, budding takes place, but the outgrowth is not stabilized and the bud degenerates (Fallon et al. 1983). The affected component is the ectoderm, as grafting of normal ectoderm to the limbless limb field results in the formation of an apical ridge and normal limb development (Carrington and Fallon 1988). The eudiplopodia mutant has the remarkable property of forming a second ectodermal ridge on the dorsal surface of the four limb buds and, as a result, exhibits duplication of the distal parts of the limbs (Goetinck 1964). This probably reflects the fact that in this mutant, the limb ectoderm does not become refractory to mesodermal induction as it does in normal chicks after the apical ridge has formed (Fraser and Abbott 1971). Here, too, the ectoderm is the affected component: Mutant mesoderm, if combined with normal ectoderm as early as stage 14 (Hamburger and Hamilton 1951), produces a normal limb (Goetinck 1964; Fraser and Abbott 1971). This mutation can be phenocopied by grafting normal flank ectoderm of stage 14-18 onto the dorsal mesoderm of a stage 17-20 normal limb bud (Carrington and Fallon 1986). 
Cells in the mesenchyme that underlie the ridge are actively dividing and remain in an embryonic state (Stark and Searls 1973; Summerbell et al. 1973). All of the data from experimental embryology show that the specific skeletal structures of the limb are determined in a proximodistal fashion and that interactions between the ridge and the underlying mesoderm are critical for this determination (Saunders 1948; Zwilling 1956; Summerbell et al. 1973; Saunders et al. 1976; Rowe and Fallon 1982). This has led Wolpert and his colleagues (Summerbell et al. 1973) to propose that this region of the mesoderm forms a progress zone where cells acquire positional information, depending on the time that they spend (or the number of cell divisions they achieve) in this zone. Diffusible factors coming from the ridge have been detected (Cairns 1975), which might establish the progress zone, but none has been isolated yet.

A number of potential regulatory genes, which may be involved in the response to such signals in the limb, have been isolated from the vertebrate genome. Notable among these are the Hox genes, which contain a homeo box related to that of Antennapedia $(A n t p)$ in Drosophila, and which are thought, based on their patterns of expression, to be involved in establishing the anteroposterior axis during development (Kessel and Gruss 1990). All of these genes are expressed in the neural tube; however, members of the Hox-4 gene cluster, for example, show distinct patterns of expression in the developing limb bud (Dollé et al. 1989).

Another potential regulatory gene expressed in the limb bud is Hox-7, which carries a homeo box that is quite different from the Antp type, but related to the Drosophila muscle segment homeo box (msh) homeo box, and is not a member of a cluster (Hill et al. 1989; Robert et al. 1989). Our initial observations have shown that at 12.5 days in the mouse embryo, Hox -7 expression is confined in the limb bud, to the apical ridge, and the subjacent mesoderm. This suggested to us that Hox-7 expression might be related to the activity of the apical ridge. A gene related to $\operatorname{Hox}_{-7}$, Hox-8, has been characterized recently in the mouse, which is also expressed in the limb bud, in and under the ridge (Davidson et al. 1991; Monaghan et al. 1991).

Therefore, we have isolated cDNAs for Hox-7 and $H o x-8$ in the chick and undertaken a systematic analysis of their expression throughout the early development of chick limb buds. Furthermore, we have made use of the limbless mutant in the chick, which does not form apical ridges, and of ectodermal grafts, which generate an extra ridge on the dorsal surface of the limb buds. We have also grafted a functional ridge from quail onto chick limb buds to generate an ectopic limb outgrowth to analyze Hox-7 and Hox-8 expression in this new context. Our observations demonstrate that expression of these genes is always associated with a functional ridge and that the patterns are reshaped if an ectopic ridge is induced. The presence of the apical ridge is not necessary for the initial induction of the two homeo box genes in the limb bud but is an absolute requirement for the maintenance of this expression. We propose that expres- sion of these two homeo box-carrying genes is maintained in the apical region of the limb bud and may be induced in ectopic sites by a diffusible factor emanating from the ridge.

\section{Results}

Specificity of the probes used for in situ hybridization

We have used a probe from the mouse Hox -7 gene, encompassing the $5^{\prime}$ two-thirds of the homeo box (Robert et al. 1989), to isolate cDNAs from related genes in the chick. This probe is devoid of the sequences encoding the third helix of the homeo domain, which are conserved over most of the homeo box-containing genes. It reveals two genes in the chick genome by Southern blot analysis under low-stringency conditions (not shown). Two types of cDNAs have been isolated and sequenced (Fig. 1), each corresponding to one of the loci characterized on Southern blots. It is clear that in spite of extensive similarity between the coding sequences of the two cDNAs, one is more related to that of $\mathrm{Hox}^{-7}$ in the mouse, and the second, to that of Hox -8 (Monaghan et al. 1991). We have therefore designated them as Hox-7 and Hox 8 in the chick, respectively.

Further characterization of these sequences relies on the analysis of their patterns of expression during embryonic development. In the chick, the two genes are expressed at the same sites, namely, the neural tube and the neural crest; the visceral arches and the frontonasal territories; the endocardial cushion, which will form the atrioventricular valves; the lateral mesoderm; and the apical ridge and underlying mesenchyme in the limb bud. Minor differences can be detected, however, in their expression. For example, Hox-7 expression occupies a larger part of the neural tube; expression is stronger for Hox -8 in the lateral mesoderm ventral to the limb bud; in the limb bud, Hox-7 expression is prominent in the mesenchyme, and weaker in the ridge, whereas it is the opposite for Hox-8; and in the endocardial cushion, Hox -7 is expressed in the endothelium and in the mesenchymal cells that derive from it, whereas Hox-8 is expressed in the myocardial part of the cushion (not shown).

In all instances, the chick Hox-7 gene behaves as its murine homolog in the mouse; therefore, not only the sequence but the expression properties of the gene are conserved between the two species. In the experiments presented here, two distinct probes covering the 3 '-untranslated region (UTR) of the chick Hox-7 or Hox-8 sequence, and therefore specific for each gene, have been used (Fig. 1).

\section{Hox -7 and Hox -8 expression is associated with the apical ridge in the limb bud}

Expression of Hox-7 is prominent in the developing limb bud. Expression is conspicuous also in the lateral mesoderm, ventral to the developing limb bud. At the earliest stages of limb budding, that is, stage 16 (for the wing bud) or 17 (for the leg bud) in the chick (Hamburger and Hamilton 1951), transcripts are detected over the entire limb 


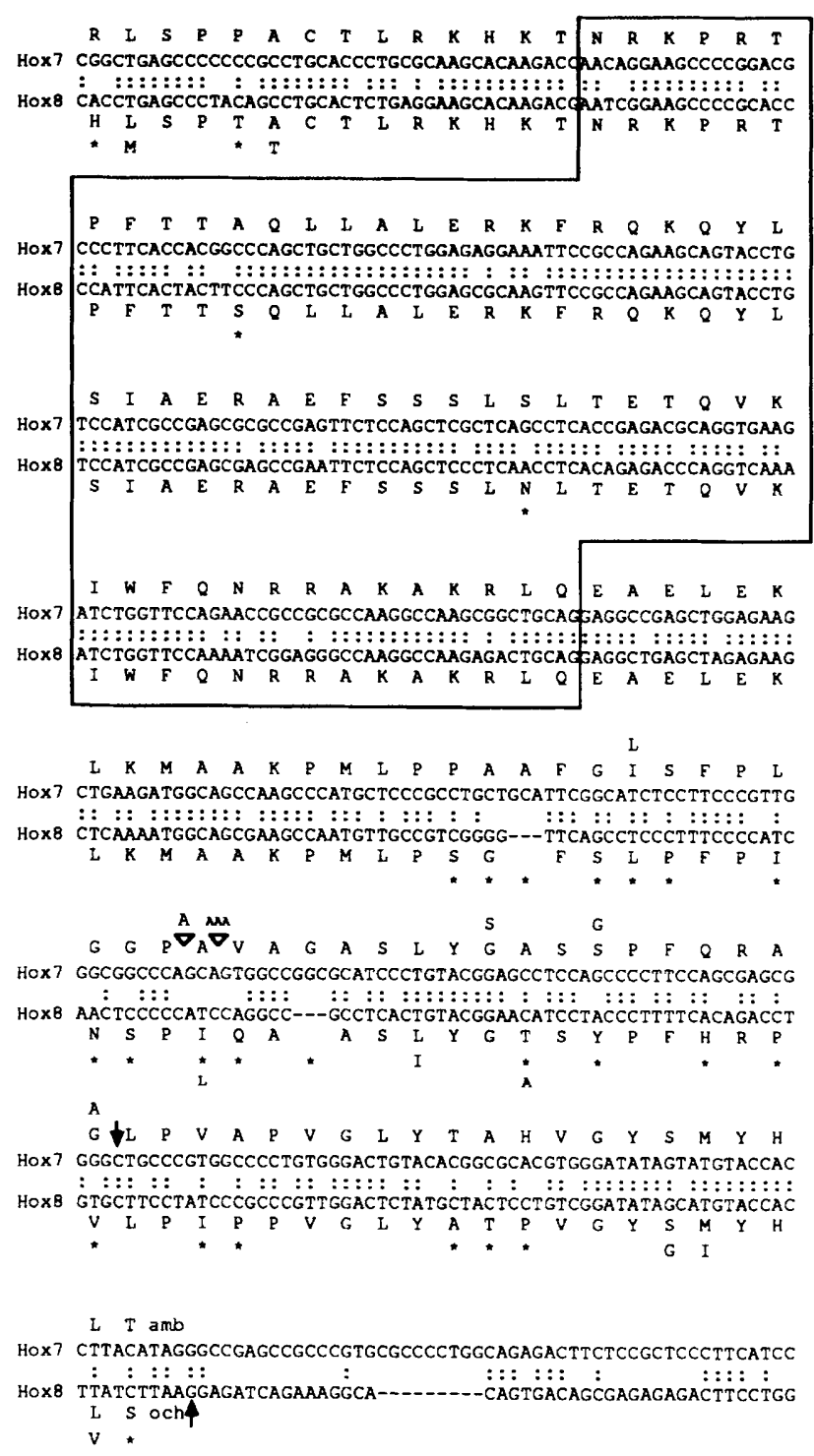

Hox7 AGACCTTCAACCCTGGGATCTGTTCTGTGCCTGGCAGGAAGGAACCCGTGGTGCAGCCCT

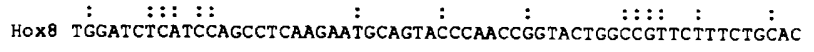

Hox7 GCTGGCAGCTGGGGAAGGAACTGTGGCAGAGAAAGGGA--CAAAGGCAGCCCAGTAGGA

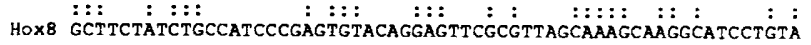

Hox7 CATTTCTGTCAAGGCAGGGTGGGAGGCAGAGCCGCCTGTCCCGTCCCTGCAGGGCAGCTG

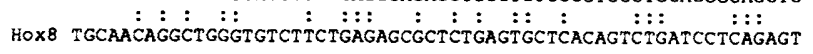

Hox? TTAACCTGTGGCCATTCCTCCGCCAGCTCCTGAGGGAAGGGGCTCTCTCTGTGTACTATG HOX8 GTTTA

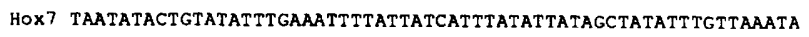

Hox 7 AatTAatTTTAagctaca
Figure 1. Sequence comparison between Hox-7 and Hox-8 cDNAs in the chick. The sequences depicted correspond to the 3 'region of both cDNAs, including the homeo box. Each substitution between chick $\mathrm{Hox}-7$ and $\mathrm{Hox}-8$ leading to a change in amino acid is marked by an asterisk $\left({ }^{*}\right)$. Divergences between the mouse (L. Ferland and B. Robert, unpubl.) and the chick Hox -7 amino acid sequences are shown above the chick Hox-7 sequence; this includes insertion of four alanines $(\nabla)$, which are found in the mouse and not in the chick cDNA. The sequence is the same at these positions in mouse and human Hox-7 cDNAs (J. Hewitt, pers. comm.). Divergences between chick and mouse (Monaghan et al. 1991) Hox-8 sequences are shown under the chick Hox 8 sequence. The sequences of chick Hox-7 and $H o x-8$ differ at 27 positions, whereas there are only 6 and 8 positions changed between the chick and the mouse $\mathrm{Hox}-7$ and Hox -8 , respectively. The boxed area marks the limits of the homeo box. The two arrows delimit the 5 ' extremities of the probes used in in situ hybridizations.

mesoderm (Fig. 2A). As development proceeds, they become localized in the mesoderm under the apical ridge (Fig. 2C,E). This is achieved at stage 20 in the chick embryo. Expression in the lateral mesoderm is retained until at least stage 26 (not shown); however, it is limited to the ventral mesoderm and does not extend dorsally to the buds themselves. We detect expression in the ectodermal ridge from stage 18 when this structure is first observed (results not shown).

Hox -8 is expressed in a very similar manner (Fig. $2 \mathrm{~B}, \mathrm{D}, \mathrm{F})$. However, in contrast to Hox -7 , its expression is higher in the lateral mesoderm and more prominent in the ridge than in the underlying mesoderm. Furthermore, Hox -8 transcripts do not show a uniform anteroposterior distribution in the mesoderm, their concentration being highest on the anterior side (Fig. 2D,F; Yokouchi et al. 1991). This is not the case for expression in the ridge itself (Fig. 2D,F).

The ridge is required for apical expression of Hox-7 and Hox-8 in the limb bud

If Hox -7 and Hox -8 expression in the limb bud depends on the ridge, it would be expected, under conditions where a functional ridge is absent, that no expression of these genes would be seen. These conditions are fulfilled in the limbless mutant of the chick, which never forms a ridge in the homozygous state, and, therefore, neither develops wings nor legs (Prahlad et al. 1979; Fallon et al. 1983). Nevertheless, limb buds appear at stage 16-17, as in the normal animal, but begin to degenerate at stage 19 and disappear by stage 24 (Fallon et al. 1983).

In this mutant, stage 19 limb buds do express $\mathrm{Hox}_{-7}$ and $H o x-8$ (Fig. 3A,B). Until this stage, no difference can be observed in the expression of these genes between normal and limbless embryos (not shown). Expression of Hox -7 is considerably reduced at stage 20 and barely detectable at stage 21 in the wing bud (Fig. 3). Hox-8 transcripts are still conspicuous at stage 21 , in the anteriormost part of the wing bud (Fig. 3) but are not detectable at stage 22 (not shown). 


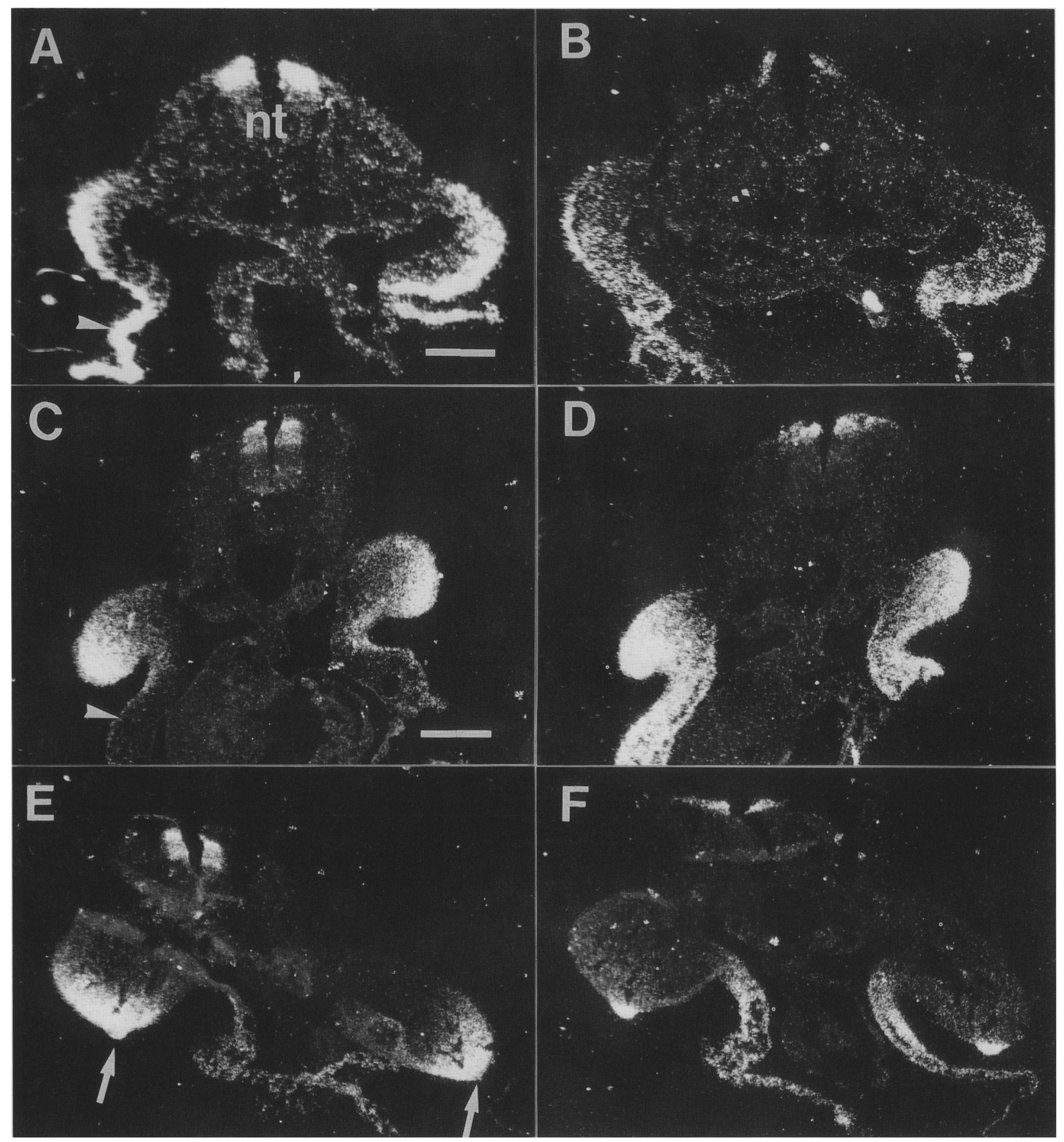

Figure 2. Evolution of $\mathrm{Hox}_{-1} 7$ and $\mathrm{Hox}_{-}-8$ expression in the limb field and the limb bud during normal chick development. All sections are transverse sections at the wing bud level. $\{A, C, E)$ Sections were hybridized with the Hox -7 probe; $\mid B, D, F)$, with the Hox-8 probe. $(A, B)$ Parallel sections of stage $16 ;\{C, D)$ parallel sections of stage 21 , from the anterior side of the wing bud; $(E, F)$ parrallel sections of stage 21, from the posterior side of the wing bud. Arrowheads $(A, C)$ indicate the lateral mesoderm ventral to the limb bud; arrows $|E|$ indicate the apical ridges. (nt) Neural tube. Bar, $100 \mu \mathrm{m}$ in $A$ and $B ; 210 \mu \mathrm{m}$ in $C-F$.

Necrosis is unlikely to be the primary cause of the disappearance of Hox-7 transcripts. First, necrosis is beginning to take place only at stage 19 ; and at stage 20 , the rate of cell division is sufficiently high to counterbalance necrosis. Therefore, the bud retains its size (B.K. Simandl and J.F. Fallon, unpubl.). At this stage, expression of Hox -7 is already much lower than in the normal animal.
Second, cells in the apical region of limbless buds are still actively transcribing other genes, at least up to stage 22 , as indicated by the hybridization of a mouse $\beta$-actin probe to a section of a limbless embryo (Fig. 4C).

Expression of Hox-7 and Hox-8 in the limb field is therefore governed by two different events, one at early stages, which is independent of the apical ridge, and the 


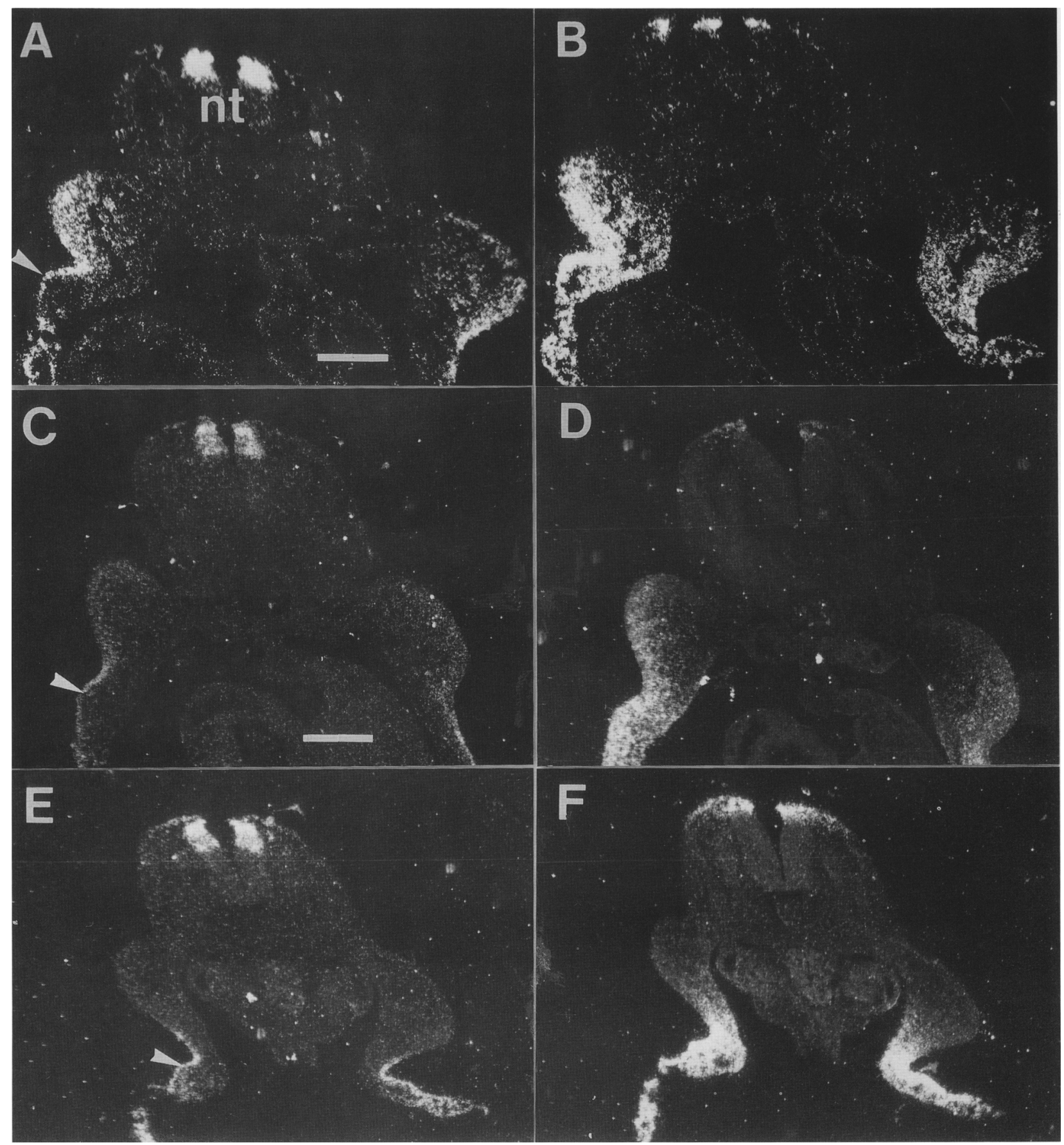

Figure 3. Expression of $H_{O X-7}$ and $H_{O X}-8$ in limbless limb field. All sections are transverse sections at the wing bud level of the limbless mutant. $(A, C, E)$ Sections were hybridized with the Hox-7 probe; $(B, D, F)$, sections were hybridized with the $H o x-8$ probe. $(A, B)$ Adjacent sections of stage 19; $(C-F)$ sections of stage 21 . Sections in $C$ and $D$ are from the anterior level; those in $E$ and $F$ are from the posterior level of the wing bud. Arrowheads in $A, C$, and $E$ indicate the lateral mesoderm ventral to the limb, where expression remains normal, as it does in the neural tube (nt). Bar, $150 \mu \mathrm{m}$ in $A$ and $B ; 210 \mu \mathrm{m}$ in $C-F$.

other around the time when limbs elongate, which depends on the ridge.

Rescuing the limbless mutation restores Hox-7 and Hox-8 expression in the limb bud

It has been demonstrated that the ectoderm is the germ layer affected in this mutant: Grafting a piece of normal flank ectoderm from stage 17 or 18 on the presumptive limb field of a stage 15 limbless mutant will rescue the mutant, allowing the formation of an apical ridge and the development of a normal wing or leg /Carrington and Fallon 1988). We rescued limbless mutant limb buds in this way and fixed them $28-40 \mathrm{hr}$ after operation. Figure 


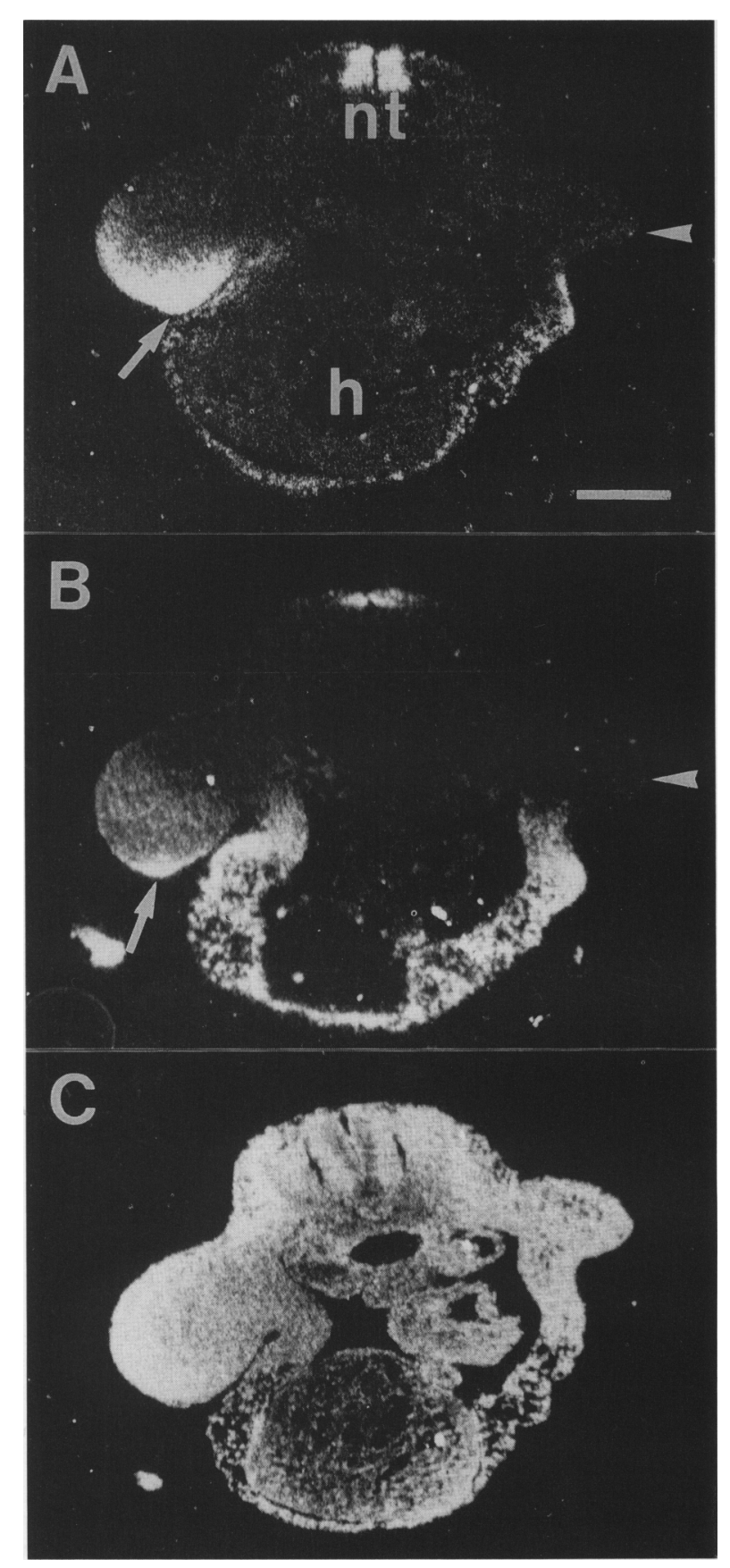

Figure 4. The effect of grafting normal ectoderm on limbless flank mesoderm. (A) Transverse section of a grafted limbless embryo at the wing bud level, hybridized with the Hox -7 probe. Note that the mesoderm promotes the formation of a ridge in the grafted ectoderm (to which the arrow points) and the outgrowth of the mesoderm from the grafted limb bud. The arrowhead indicates the ungrafted limb bud. (nt) Neural tube; (h) heart. $(B)$ A parallel transverse section hybridized with the $H o x-8$ probe. As in $A$, the section is from the anterior level of the wing bud. $(C)$ A section adjacent to that shown in $A$ hybridized with a $\beta$-actin probe, showing that expression of this gene is still intense in the regressing limb bud. Bar, $270 \mu \mathrm{m}$.
4 shows that this permits a ridge to form and results in a normal outgrowth of the limb bud on the grafted side. The grafted normal ectoderm that has formed a ridge now expresses $\mathrm{Hox}-7$ and $\mathrm{Hox}-8$. It also restores the expression of both genes in the mesenchyme underlying the ridge. This indicates further that neither the Hox-7 or Hox -8 gene itself is likely to be affected in the limbless mutant, which is corroborated by the fact that expression of the two genes is normal at other sites, such as the neural tube and the lateral mesoderm in the mutant (Figs. 2 and 3). It agrees also with the very specific effect of the mutation, which affects only limb development (Fallon et al. 1983).

\section{An ectopic ridge will induce and sustain ectopic} Hox -7 and Hox -8 expression

The eudiplopodia mutant is characterized by its ability to generate an ectopic ectodermal ridge on the dorsal surface of the limb bud. As this second ridge is formed at about stage 24 , several stages after the apical ridge is active, it induces the formation of only part of an extra limb, leading to duplication of the most distal elements of the skeleton (Goetinck 1964). It is possible to produce eudiplopodia phenocopies by grafting flank ectoderm from a stage 17-18 donor onto the dorsal surface of the limb bud of a stage 18 host embryo /Carrington and Fallon 1986). As the flank ectoderm at this stage is still competent to respond to mesodermal induction, it forms an ectodermal ridge that promotes the outgrowth of subjacent mesoderm. The supernumerary outgrowth resulting from such a graft has been analyzed for the expression of Hox-7 and Hox-8, $50 \mathrm{hr}$ after the operation, as shown in Figure 5 for a wing bud. A similar result was observed when the graft was performed on a leg bud (not shown). Expression of the two genes takes place in each of the ectodermal ridges, apical and ectopic, and in the mesoderm that underlies each of them.

At stage 18, when the grafting of ectoderm was performed, expression of $\mathrm{Hox}-7$ and $\mathrm{Hox}-8$ is widespread over the limb bud mesoderm. To determine whether the ridge not only stabilizes the expression of these genes but also can induce their expression de novo, we undertook another series of experiments. We grafted a functional ridge from a quail leg bud (stage 20-22) onto the proximal dorsal surface of a chick wing bud istage 2223). At this stage, neither Hox -7 nor Hox -8 is expressed in this region of the limb bud mesoderm. Twenty-eight hours later, the quail ridge has induced an outgrowth from the grafted limb. Hox -7 and $H o x-8$ are both expressed in the new outgrowth (Fig. 6A,B), demonstrating that the ridge can induce expression of the two genes in the limb bud mesoderm.

Feulgen staining of sections from these specimens allowed the distinction between quail and chick cells, on the basis of their heterochromatin distribution (Le Douarin 1969). Quail cells were confined to the ectodermal component of the outgrowth and found mainly in the ridge and, for a few cell widths, in the ectoderm lateral to it (Fig. 6D). The mesoderm is formed entirely of 


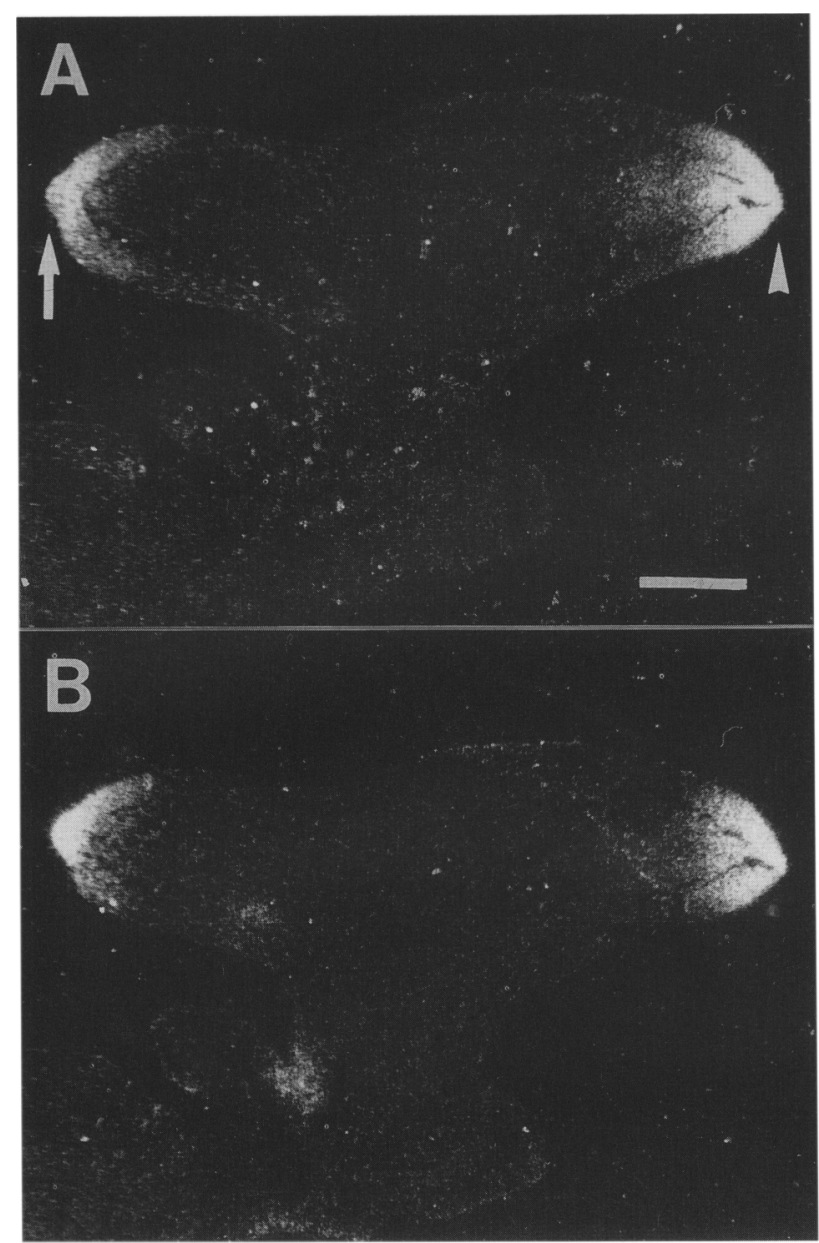

Figure 5. Hox-7 and Hox-8 expression in a eudiplopodia phenocopy. Grafted wing bud was dissected from the host and sectioned sagittally along the proximodistal axis of the limb. The section in $A$ was hybridized with the $H_{0 x}-7$ probe; that in $B$, with the Hox -8 probe. The arrowhead indicates the apical ridge; the arrow denotes the ectopic ridge formed by the grafted flank ectoderm. This ectopic ridge promotes the outgrowth of a supernumerary bud. Bar, $270 \mu \mathrm{m}$.

chick cells in which Hox-7 and Hox -8 transcripts can be detected (Fig. 6A,B). This demonstrates that the expression of Hox-7 and Hox-8 in the outgrowth mesoderm has been induced in the chick tissues and is not provided by contaminating quail mesoderm brought with the graft.

\section{Discussion}

In the chick, Hox-7 and Hox-8 expression becomes restricted in the limb bud mesoderm to the region underlying the apical ridge, between embryonic stages 20 and 21 . The same restriction in expression is observed for Hox-7 in the mouse embryo between day 10 and 11 of gestation (G.E. Lyons et al., unpubl.). We have used a chick mutant that is unable to form an apical ridge and generated chickens that have limb buds with an extra ridge, to demonstrate that the maintenance of $\mathrm{Hox}_{-7}$ and Hox-8 expression in the limb bud depends on the presence of a functional ridge and that ectopic expression may be induced and maintained by an ectopic ridge.

For this project, we isolated cDNAs for chick Hox-7 and Hox-8. One such gene has also been reported for the quail (Takahashi and Le Douarin 1990) and recently for the chick (Coelho et al. 1991). The fact that we isolated only two types of sequences and that they correspond to the two loci detected on Southern blot with a homeo box probe from mouse Hox-7 under low-stringency conditions suggests that there are only two closely related genes carrying a homeo box of the msh type in the chick genome. This is in contrast to the results of Holland (1991), which indicate the presence of three msh-related genes in the mouse genome and three in the zebra fish genome. Only two msh-type genes, however, have been isolated from Xenopus (Su et al. 1991). This suggests that there have been duplications of $m s h$-related genes in the different phyla of vertebrates leading to variable multiplicity in different species. Alternatively, further mshrelated genes may remain to be identified.

The site of expression of Hox-7 in stage 21 limb bud mesoderm coincides with the region of influence of the ridge, evaluated to be between 100 and $300 \mu \mathrm{m}$ (Summerbell et al. 1973; Cairns 1975; Rowe et al. 1982; Krabbenhoft and Fallon 1989). The mesoderm in this region has long been recognized to be endowed with specific properties, on the basis of a number of observations described above in the introductory section. Hox 8 is expressed in the same domain of the limb bud but mostly on its anterior side. This suggests that $H o x-8$ expression is affected by the polarizing zone, a region in the mesoderm on the posterior side of the limb bud that is involved in the anteroposterior patterning of the limb (Saunders and Gasseling 1968; Tickle et al. 1975). Application of retinoic acid at the anterior margin of the limb bud, which mimics the effect of the polarizing zone (Tickle et al. 1982), has been shown to reduce the expression of Hox -8 in the anterior mesoderm (Yokouchi et al. 1991). At earlier stages, before stage 20, the whole limb bud expresses Hox-7 and Hox-8. This may suggest that the whole bud mesoderm, at these stages, is influenced by the ridge, as is the apical mesoderm at later stages. Alternatively, the early expression in limb bud mesoderm may remain from the general expression observed in the lateral mesoderm at early stages, before budding occurs (see below).

Expression of Hox-7 and Hox-8 is tightly correlated with the activity of the ridge. In limbless mutants, no apical ridge forms but budding of the mesoderm occurs at stage 17 , and limb buds grow through stage 20 , when necrosis starts to prevail over cell division (Fallon et al. 1983). In this mutant, Hox -7 transcripts can be detected in the wing bud up to stage 19 , but they are much reduced at stage 20 when compared with normal embryos. Disappearance of Hox-8 transcripts takes place a little later, but their level is low at stage 21. Even at stage 20, necrosis is not extensive, as indicated by the presence of 


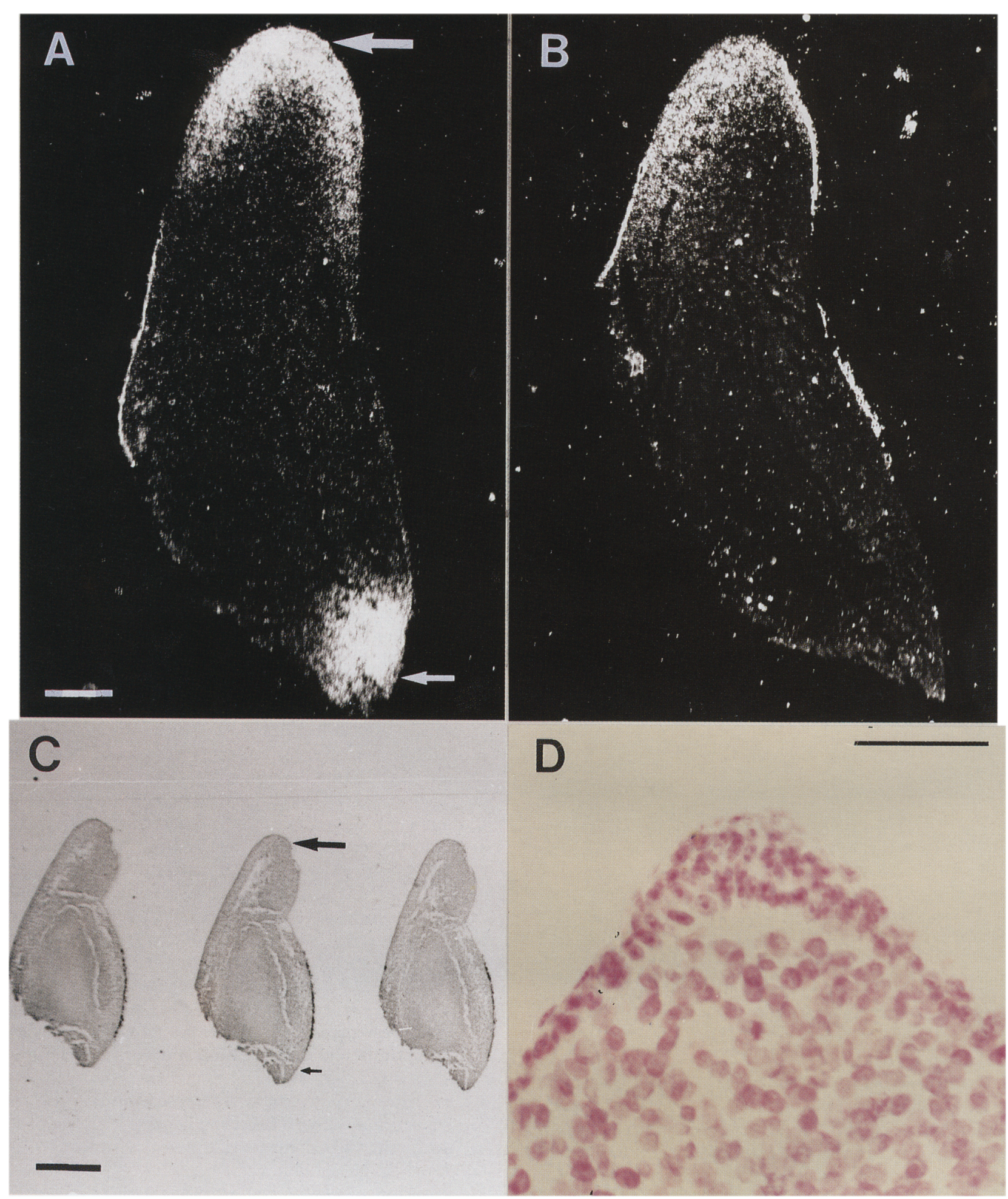

Figure 6. Expression of $\mathrm{Hox}_{-7} 7$ and $\mathrm{Hox}-8$ is induced by the grafting of a functional ridge. $|A|$ Cross section through the apical region of the outgrowth induced by a grafted quail ridge. This section was hybridized with the Hox -7 probe. The larger arrow points to the grafted ridge and the smaller one to the host ridge, which is sectioned in its lateral part $($ see $C)$. $(B)$ A parallel section to that shown in $A$, hybridized with the Hox- 8 probe. The signal on the surface ectoderm in $A$ and $B$ comes from carbon particles that were deposited on the host limb bud to orientate the graft and not from silver grains. $|C|$ Serial sections showing the structure of the grafted limb bud, with the supernumerary outgrowth extending posteriorly (large arrow). In three such graftings, this supernumerary outgrowth elongated in a posterior direction, not remaining parallel to the host axis of growth. This may be due to differential growth by anterior and posterior limb mesenchyme, which causes the limb to twist (Bowen et al. 1989). All three specimens exhibited the same pattern of expression for $\operatorname{Hox}_{-7}$ and Hox-8. The small arrow points to the host ridge, as in $A$. (D) Feulgen staining of a section from a grafted specimen. Quail nuclei contain clumps of heterochromatin; chick nuclei do not. Quail cells are restricted to the ectoderm, whereas the mesenchyme, in which $\mathrm{Hox}_{-7}$ and $H_{0 X} \cdot 8$ expression takes place $\{$ see $A, B\}$, is formed exclusively of chick cells. Bars, $120 \mu \mathrm{m}$ in $A$ and $B ; 300 \mu \mathrm{m}$ in $C ; 30 \mu \mathrm{m}$ in $D$. 
$\beta$-actin transcripts, and cannot explain the reduction in the level of Hox-7 expression in all cells of the mesenchyme. It is more likely that the ridge is required for the continued expression of Hox-7 and Hox-8.

Therefore, there are clearly two phases involved in the expression of these genes in the limb field. Before a ridge forms, Hox-7 and Hox-8 expression is already observed in the lateral mesoderm, on its ventral side. That this expression is independent of any ridge activity is confirmed further by the fact that the limbless mutant, which never forms an apical ridge, nevertheless exhibits Hox-7 and Hox-8 expression in the early limb bud. Continued expression in the apical region of the limb bud, however, is dependent on the ridge, as it is not maintained in the limbless mutant. In a similar manner, expression of the quail Hox- 8 gene in the neural crest-derived mesenchyme of the mandibular arch has been shown to depend on ectomesodermal interactions, which are also critical for bone differentiation in this arch (Takahashi et al. 1991).

The limbless mutant can be rescued by grafting normal ectoderm in the limb field at an early stage. This allows the formation of a ridge and differentiation of a normal limb (Carrington and Fallon 1988). In this ridge and in the underlying mesoderm, Hox-7 and Hox-8 expression takes place, demonstrating that the formation of an apical ridge is sufficient to maintain the expression of the two genes. This is confirmed by an analysis of eudiplopodia phenocopies, produced by grafting flank ectoderm onto the dorsal surface of the limb bud. These buds form an ectopic ectodermal ridge and produce a supernumerary outgrowth of the limb mesoderm, resulting in a partial duplication of the limb. Together with these morphological events, Hox -7 and Hox -8 expression is prominent in the ectopic ridge and in the mesenchyme, which grows under the influence of this ridge.

Is the ridge the inducer of $\mathrm{Hox}_{-7} \mathrm{and}$ aox-8 expression in the limb bud? This question is not solved by the grafting experiments leading to limbless rescue or to $\mathrm{eu}$ diplopodia phenocopies, as, in these, the ectoderm is grafted at an early stage of limb development, when expression of the two genes is widespread over the whole limb field. The effect of the ridge might be to stabilize Hox-7 and Hox -8 expression in certain limb cells, rather than to induce it. To distinguish between these two possibilities, we have grafted a functional quail ridge onto the proximodorsal surface of a stage 22-23 chick limb bud, a region that is not the site of $\mathrm{Hox}_{-1}$ or $\mathrm{Hox}_{-} 8 \mathrm{ex}$ pression at this stage. Expression of both genes is observed in the mesoderm of the outgrowth that results from the graft, demonstrating that the ridge is capable of activation of Hox-7 and Hox-8 expression. This conclusion was also reached by Davidson et al. (1991), who have shown recently that expression of $\mathrm{Hox}-7$ and Hox-8 in mouse limb bud mesoderm grafted into chick limb buds depends on the position of the grafted mesoderm in relation to the host ridge.

The ridge could exert its effects on the underlying mesenchyme in a number of ways. The pattern of distribution of Hox-7 transcripts under the ridge is evocative of a regulation by a diffusible factor, because the concentration of the transcripts is at its highest beneath the ectodermal layer and then decreases in a graded fashion. The same factor might be responsible for the induction of $H o x-8$, although its distribution does not quite overlap with $H o x-7$. This difference in the patterns of expression of $\mathrm{Hox}_{-7}$ and Hox-8 may be related to the fact that the latter is affected by the polarizing zone; therefore, its expression is very low on the posterior side in the mesoderm (Yokouchi et al. 1991). The fact that Hox-8 transcripts continue to be detected in limbless limb buds one stage later than $\mathrm{Hox}_{-7}$ transcripts suggests that the former is slightly less dependent on the ridge, perhaps because Hox -8 transcripts are more stable.

The existence of diffusible factors produced by the apical ridge has been shown by Cairns (1975), by testing the viability of limb mesenchyme in culture. The mesenchymal cells show widespread necrosis after $10 \mathrm{hr}$ of culture if they are not associated with a ridge, and even if they are associated with nonridge ectoderm. If they are associated with the ridge, no necrosis occurs for up to $24 \mathrm{hr}$ of culture. The maintenance function does not require contact between ectoderm and mesoderm, as cell death is prevented if ridges are suspended in the culture medium. The nature of such diffusible factors has not yet been determined. A number of molecules, however, could fulfill these functions, as they have the distribution pattern expected for an inducer: growth factors from the TGF- $\beta$ family (Heine et al. 1987), particularly BMP2A (Lyons et al. 1990a) and BMP-4A (Jones et al. 1991), or Wnt-1-related genes (Gavin et al. 1990). Such factors may regulate $\mathrm{Hox}_{-1} \mathrm{\text {and }}$ Hox-8 expression: This would imply that both cells in the ectoderm and in the underlying mesoderm are responsive to them. Ectodermal expression of the two genes is clearly present in the ridge and does not extend beyond the respective domains of expression of each gene in the underlying mesoderm (see Fig. 2E,F). The intimate association between ectodermal and mesodermal expression of each gene is clearly demonstrated by Yokouchi et al. (1991). This is demonstrated further in the limbless mutant where the ectoderm, which does not form a ridge, as well as the underlying mesoderm, is negative for Hox-7 and Hox-8 transcripts.

From their pattern of expression and from the fact that they both depend on the apical ridge for their expression, HoX -7 and HoX -8 may act as determinants of the progress zone. One of the functions of $\mathrm{Hox}_{-7}$ may be to prevent differentiation in this domain. It is striking that at later stages of limb development, Hox-7 expression is observed in the interdigital region (Robert et al. 1989), a site where cartilage differentiation is prevented by the overlying ectoderm (Hurle et al. 1989).

In conclusion, our results demonstrate that continued

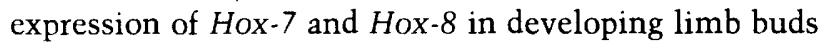
is dependent on a functional ridge. The nature of ectodermal-mesodermal interactions in the formation of the ridge and in the maintenance of the progress zone remains to be elucidated. However, it is clear that Hox -7 and $H o x-8$ are likely to play important roles in these developmental processes. 


\section{Robert et al.}

\section{Materials and methods}

\section{Isolation of $c D N A s$}

Hox -8 (or Msx-1) cDNA was isolated as described by Yokouchi et al. (1991).

Hox-7 cDNA was isolated from a chick cDNA library cloned into Lambda ZAPII (Stratagene) (a kind gift from Rolf Zeller, EMBL). The cDNA was prepared from stage 19-23 total chick embryo RNA. Phages $\left\{2 \times 10^{6}\right\}$ from the unamplified library were screened using a mouse probe comprising the first 100 nucleotides from the homeo box plus 50 nucleotides $5^{\prime}$ of it (Robert et al. 1989), under low-stringency conditions (hybridization in $35 \%$ formamide, $0.875 \mathrm{M} \mathrm{Na}^{+}$, for $15 \mathrm{hr}$ at $37^{\circ} \mathrm{C}$; final wash in $0.2 \times \mathrm{SSC}, 1 \% \mathrm{SDS}$, at $55^{\circ} \mathrm{C}$. Positive phages were plaque purified, and recombinant BlueScript plasmids were excised using M13 helper phage. Sequencing was performed using the Sequenase kit (U.S. Biochemical), on single- or doublestranded DNA. Chicken Hox -7 and Hox -8 sequences are available from EMBL data library under accession numbers X61922 and X62541, respectively.

\section{Embryologic manipulations}

Homozygous limbless embryos were obtained from mating members of a heterozygous breeding stock maintained at the University of Wisconsin (Madison, WI). After stage 19, the limb buds of homozygous limbless embryos are morphologically distinguishable from those of normal embryos. To analyze embryos before this stage, either limb buds or the whole posterior part of the embryo were dissected out and fixed while the rest of the embryo was allowed to develop until its phenotype could be identified.

Rescue of limbless mutants by the grafting of normal ectoderm to the wing field of stage 14-15 prospective mutant embryos was as described in Carrington and Fallon (1984). Donor flanks from normal stage 18-19 embryos were removed from the donor, and the neural tubes were cut away. The left and right flanks were treated with Dispase II (Boehringer Mannheim) diluted $1: 2$ in Earle's balanced salt solution (EBSS) for $10-15 \mathrm{~min}$ at $37^{\circ} \mathrm{C}$, and the ectoderm was separated from the mesoderm with fine forceps. Ectoderm pieces were then placed in 10\% horse serum in EBSS and held on ice until grafting. Prospective limbless host embryos were prepared as follows. After removal of overlying membranes, the wing field was lightly stained with Nile Blue A and the presumptive right wing bud ectoderm was gently teased away with a fine glass needle and forceps. Two pieces of flank ectoderm were then pipetted to the host, positioned in an overlapping fashion over the wing field, pressed into place, and allowed to heal at room temperature for $30 \mathrm{~min}$ to $1 \mathrm{hr}$ before the egg was reincubated. Twentyfour hours later, the phenotype of the host was identifiable. Limbless embryos with rescued wings were fixed at $28-40 \mathrm{hr}$ postoperatively. The embryo that formed the most conspicuous ridge was processed for analysis by in situ hybridization.

eudiplopodia phenocopies were made essentially as described by Carrington and Fallon (1986), except that we used Dispase II for separation of the mesoderm and the ectoderm. Briefly, the flank tissue between the wing and the leg buds of a stage 17 or 18 embryo was incubated in Dispase II diluted $1: 2$ in EBSS for $10 \mathrm{~min}$ at $37^{\circ} \mathrm{C}$. The flank was transferred to $3 \%$ chick serum in EBSS, where we separated the ectoderm and the mesoderm. The mesoderm was discarded, and the ectoderm was held on ice until grafted. The graft site on the stage 18 host limb bud was prepared by peeling away the dorsal limb ectoderm with sharpened tungsten needles to expose the dorsal limb bud mesoderm.
The ectoderm was removed from the egg and discarded. The donor ectoderm was transferred by pipette to the host egg and was then draped over the denuded mesoderm. The egg was left undisturbed for $\sim 1 \mathrm{hr}$ at room temperature to permit the ectoderm to stick to the graft site before reincubating the egg. The host embryos were allowed to develop $50 \mathrm{hr}$ postoperatively and were then fixed and processed for in situ hybridization.

The techniques used for grafting quail ridges were similar to those above, except the donors and the hosts were older. The donor ridges were isolated from stage 20-22 quail leg buds. The distal tips of the buds were isolated and transferred to Dispase II for $\sim 15 \mathrm{~min}$ at $37^{\circ} \mathrm{C}$. The tissue was transferred to $3 \%$ chick serum in EBSS where the ectoderm was peeled off the mesoderm. The mesoderm was discarded. This procedure yields a rectangular piece of ectoderm with the apical ridge in the center, flanked by dorsal and ventral ectoderm. The graft site was prepared by peeling the ectoderm off the proximal, dorsal surface of the stage 22 or 23 host wing bud. The denuded mesoderm expresses neither Hox-7 nor Hox-8. The donor ectoderm was transferred to the host egg and draped over the denuded site, aligning the donor ridge with the host ridge. The embryos were held at room temperature for $1 \mathrm{hr}$ to increase the chance that the graft would stick. The grafted limbs were fixed $40 \mathrm{hr}$ postoperatively for in situ hybridization.

\section{In situ hybridization}

In situ hybridization was performed on 5- to $7-\mu \mathrm{m}$ paraffin sections. The procedures used for section treatment, hybridization, and washings are described by Lyons et al. (1990b). Hybridization was carried out at $50^{\circ} \mathrm{C}$ for $\sim 16 \mathrm{hr}$ in $50 \%$ deionized formamide, $0.3 \mathrm{M} \mathrm{NaCl}, 20 \mathrm{~mm}$ Tris- $\mathrm{HCl}(\mathrm{pH} 7.4), 5 \mathrm{~mm}$ EDTA, 10 $\mathrm{mm}$ sodium phosphate $(\mathrm{pH} 8), 10 \%$ dextran sulfate, $1 \times$ Denhardt's solution, $50 \mathrm{mg} / \mathrm{ml}$ of yeast RNA, with $50-75,000 \mathrm{dpm} /$ $\mu \mathrm{l}$ of cRNA labeled with ${ }^{35} \mathrm{~S}$-labeled UTP $>1000 \mathrm{Ci} / \mathrm{mmole}$, Amersham). Washing was at $65^{\circ} \mathrm{C}$ in $50 \%$ formamide, $2 \times \mathrm{SSC}$, and $10 \mathrm{~mm}$ DTT. Slides were then treated with RNase A 120 $\mathrm{mg} / \mathrm{ml}$ ) (Boehringer Mannheim) for $30 \mathrm{~min}$ at $37^{\circ} \mathrm{C}$. After washes, slides were processed for standard autoradiography with Kodak NTB-2 nuclear track emulsion and exposed for 7 days. Analysis was carried out with both light- and dark-field optics on a Zeiss Axiophot microscope.

For each stage, at least two animals of normal or limbless phenotype were sectioned and analyzed by in situ hybridization. The description of the transcript distribution patterns presented in the text summarizes all of our observations.

The probes were derived from the $3^{\prime}$-UTR of either gene. For Hox-7, a DNA fragment encompassing the T3 promoter in the BlueScript plasmid and extending into the coding region, as depicted in Figure 1, was amplified by polymerase chain reaction (PCR) and used as a template to synthesize a cRNA. For Hox-8, the Msx-l plasmid was restricted with $A f l$ III (see Fig. 1) and a cRNA synthesized from the T7 promoter in the vector.

The mouse $\beta$-actin probe is a PStI fragment containing $1.1 \mathrm{~kb}$ of the coding sequence, cloned into the PstI site of BlueScribe $1+1$ (Alonso et al. 1986). The plasmid was linearized with EcoRI and transcribed with the $\mathrm{T} 3$ polymerase.

\section{Acknowledgments}

We thank John F. Fallon and Karen Krabbenhoft very much for providing material and advice. We are very grateful to Rolf Zeller and Patricia A. Blundell for their generous help with the screening of the cDNA library, and to Robert Hill and Jane Hewitt for communicating sequences before publication. We 
thank Odette Jaffrezou and Dominique Sireta for technical assistance. G.L. held a National Institutes of Health/Centre National de la Recherche Scientifique (NIH/CNRS) fellowship from the Fogarty International Center. This work was supported by grants from the Institut Pasteur, CNRS, Association pour la Recherche sur le Cancer (ARC), and Institut National de la Santé et de la Recherche Médicale (INSERM) to M.B. B.K.S. was supported by NIH grant POIHD20743.

The publication costs of this article were defrayed in part by payment of page charges. This article must therefore be hereby marked "advertisement" in accordance with 18 USC section 1734 solely to indicate this fact.

\section{References}

Alonso, S., A. Minty, Y. Bourlet, and M. Buckingham. 1986. Comparison of three actin-coding sequences in the mouse; evolutionary relationships between the actin genes of warmblooded vertebrates. J. Mol. Evol. 23: 11-22.

Bowen, J., J.R. Hinchliffe, T.J. Horder, and A.M. Reeve. 1989. The fate map of the chick forelimb-bud and its bearing on hypothesized developmental control mechanisms. Anat. Embryol. 179: 269-283.

Cairns, J.M. 1975. The function of the ectodermal apical ridge and distinctive characteristics of adjacent distal mesoderm in the avian wing bud. I. Embryol. Exp. Morphol. 34: 155169.

Carrington, J.L. and J.F. Fallon. 1984. The stages of flank ectoderm capable of responding to ridge induction in the chick embryo. J. Embryol. Exp. Morphol. 84: 19-34.

1986. Experimental manipulation leading to induction of dorsal ectodermal ridges on normal limb buds results in a phenocopy of the eudiplopodia chick mutant. Dev. Biol. 116: 130-137.

1988. Initial limb budding is independent of apical ectodermal ridge activity; evidence from a limbless mutant. Development 104: 361-367.

Coelho, C.N.D., L. Sumoy, B.J. Rodgers, D.R. Davidson, R.E. Hill, W.B. Upholt, and R.A. Kosher. 1991. Expression of the chicken homeobox-containing gene GHox-8 during embryonic chick limb development. Mech. Dev. 34: 143-154.

Davidson, D.R., A. Crawley, R.E. Hill, and C. Tickle. 1991. Position-dependent expression of two related homeo box genes in developing vertebrate limbs. Nature 352: 429-431.

Dhouailly, D. and M. Kieny. 1972. The capacity of the flank somatic mesoderm of early bird embryos to participate in limb development. Dev. Biol. 28: 162-175.

Dollé, P., J.-C. Izpisua-Belmonte, H. Falkenstein, A. Renucci, and D. Duboule. 1989. Coordinate expression of the murine Hox-5 complex homoeobox-containing genes during limb pattern formation. Nature 342: 767-772.

Fallon, J.F., J.M. Frederick, J.L. Carrington, M.E. Lanser, and B.K. Simandl. 1983. Studies on a limbless mutant in the chick embryo. In Limb development and regeneration (ed. J.F. Fallon and A.I. Caplan), Part A, pp. 33-43. Alan R. Liss, New York.

Fraser, R.A. and U.K. Abbott. 1971. Studies on limb morphogenesis VI. Experiments with early stages of the polydactylous mutant eudiplopodia. I. Exp. Zool. 176: 237-248.

Gavin, B.J., J.A. McMahon, and A.P. McMahon. 1990. Expression of multiple novel Wnt-1/int-1-related genes during fetal and adult mouse development. Genes \& Dev. 4: 2319-2332.

Goetinck, P.F. 1964. Studies on limb morphogenesis II. Experiments with the polydactylous mutant eudiplopodia. Dev. Biol. 10: 71-91.

Hamburger, V. and H.L. Hamilton. 1951. A series of normal stages in the development of the chick embryo. I. Morphol. 88: 49-92.

Harrison, R.G. 1931. Experiments on the development and growth of limbs in the Amphibia. Science 74: 575-576.

Heine, U.I., E.F. Munoz, K.C. Flanders, L.R. Ellingsworth, H.Y.P. Lam, N.L. Thompson, A.B. Roberts, and M.B. Sporn. 1987. Role of transforming growth factor- $\beta$ in the development of the mouse embryo. J. Cell Biol. 105: 2861-2876.

Hill, R.E., P.F. Jones, A.R. Rees, C.M. Sime, M.J. Justice, N.G. Copeland, N.A. Jenkins, E. Graham, and D.R. Davidson. 1989. A new family of mouse homeo box-containing genes: Molecular structure, chromosomal location, and developmental expression of Hox-7.1. Genes \& Dev. 3: 26-37.

Holland, P.W.H. 1991. Cloning and evolutionary analysis of msh-like homeobox genes from mouse, zebrafish and ascidian. Gene 98: 253-257.

Hurle, J.M., Y. Gañan, and D. Macias. 1989. Experimental anal$y$ sis of the in vivo chondrogenic potential of the interdigital mesenchyme of the chick leg bud subjected to local ectodermal removal. Dev. Biol. 132: 368-374.

Jones, C.M., K.M. Lyons, and B.L.M. Hogan. 1991. Involvement of Bone Morphogenetic Protein-4 (BMP-4) and Vgr-1 in morphogenesis and neurogenesis in the mouse. Development 111: $531-542$.

Kessel, M. and P. Gruss. 1990. Murine developmental control genes. Science 249: 374-379.

Kieny, M. 1960. Rôle inducteur du mésoderme dans la différenciation précoce du bourgeon de membre chez l'embryon de poulet. J. Embryol. Exp. Morphol. 8: 457-467.

Krabbenhoft, K.M. and J.F. Fallon. 1989. The formation of legand wing-specific structures by leg bud cells grafted to the wing bud is influenced by proximity to the apical ridge. Dev. Biol. 131: 373-382.

Le Douarin, N. 1969. Particularités du noyau interphasique chez la caille japonaise (Colurnix colurnix japonica). Utilisation de ces particularités comme "marquage biologique" dans les recherches sur les interactions tissulaires et les migrations cellulaires au cours de l'ontogenèse. Bull. Biol. Fr. Belg. 103: 435-452.

Lyons, K.M., R.W. Pelton, and B.L.M. Hogan. 1990a. Organogenesis and pattern formation in the mouse: RNA distribution patterns suggest a role for Bone Morphogenetic Protein 2-A (BMP-2A). Development 109: 833-844.

Lyons, G.E., M. Ontell, R. Cox, D. Sassoon, and M. Buckingham. 1990b. The expression of myosin genes in developing skeletal muscle in the mouse embryo. I. Cell Biol. 111: 1465-1476.

Monaghan, A.P., D.D. Davidson, C. Sime, E. Graham, R. Baldock, S.S. Bhattacharya, and R.E. Hill. 1991. The msh-like homeo box genes define domains in the developing eye. Development 112: 1053-1061.

Prahlad, K.V., G. Skala, D.G. Jones, and W. Briles. 1979. Limbless: A new genetic mutant in the chick. I. Exp. Zool. 209: 427-434.

Robert, B., D. Sassoon, B. Jacq, W. Gehring, and M. Buckingham. 1989. Hox -7, a mouse homeo box gene with a novel pattern of expression during embryogenesis. EMBO I. 8: 91-100.

Rowe, D.A. and J.F. Fallon. 1982. The proximodistal determination of skeletal parts in the developing chick leg. $/ . E m$ bryol. Exp. Morphol. 68: 1-7.

Rowe, D.A., J.A. Cairns, and J.F. Fallon. 1982. Spatial and temporal patterns of cell death in limb bud mesoderm after apical ridge removal. Dev. Biol. 93: 83-91.

Saunders, J.W., Jr. 1948. The proximo-distal sequence of origin of the parts of the chick wing and the role of the ectoderm. I. Exp. Zool. 108: 363-403. 


\section{Robert et al.}

1977. The experimental analysis of chick limb bud development. In Vertebrate $\mathrm{limb}$ and somite morphogenesis (ed. D. A. Ede, J.R. Hinchliffe, and M. Balls), pp. 1-24. Cambridge University Press, Cambridge, England.

Saunders, J.W. Jr. and M.T. Gasseling. 1968. Ectodermal-mesodermal interactions in the origin of limb symmetry. In Epithelial-mesenchymal interactions (ed. R. Fleischmajer and R.E. Billingham), pp. 78-97. Williams and Wilkins, Baltimore, MD.

Saunders, J.W. Jr. and C. Reuss. 1974. Inductive and axial properties of prospective wing-bud mesoderm in the chick embryo. Dev. Biol. 38: 41-50.

Saunders, J.W. Jr., M.T. Gasseling, and J.E. Errick. 1976. Inductive activity and enduring cellular constitution of a supernumerary apical ectodermal ridge grafted to the limb bud of the chick embryo. Dev. Biol. 50: 16-25.

Stark, R.J. and R.L. Searls. 1973. A description of chick wing bud development and a model of limb morphogenesis. Dev. Biol. 33: 138-153.

Su, M.-W., H.R. Suzuki, M. Solursh, and F. Ramirez. 1991. Progressively restricted expression of a new homeo box-containing gene during Xenopus laevis embryogenesis. Development 111: 1179-1187.

Summerbell, D. 1974. A quantitative analysis of the effect of excision of the AER from the chick limb-bud. J. Embryol. Exp. Morphol. 32: 651-660.

Summerbell, D., J.H. Lewis, and L. Wolpert. 1973. Positional information in chick limb morphogenesis. Nature 244: 492496.

Takahashi, Y. and N. Le Douarin. 1990. cDNA cloning of a quail homeo box gene and its expression in neural crest-derived mesenchyme and lateral plate mesoderm. Proc. Natl. Acad. Sci. 87: 7482-7486.

Takahashi, Y., M. Bontoux, and N.M. Le Douarin. 1991. Epithelio-mesenchymal interactions are critical for Quox $7 \mathrm{ex}$ pression and membrane bone differentiation in the neural crest derived mandibular mesenchyme. EMBO /. 10: 23872393.

Tickle, C., D. Summerbell, and L. Wolpert. 1975. Positional signaling and specification of digits in chick limb morphogenesis. Nature 254: 199-202.

Tickle, C., B. Alberts, L. Wolpert, and L. Lee. 1982. Local application of retinoic acid to the limb bud mimics the action of the polarizing region. Nature 296: 564-566.

Tschumi, P.A. 1957. The growth of the hindlimb bud of Xenopus laevis and its dependence upon the epidermis. I. Anat. 91: 149-173.

Yokouchi, Y., K. Ohsugi, H. Sasaki, and A. Kuroiwa. 1991. Chicken homeobox gene Msn-1: structure, expression in limb buds and effect of retinoic acid. Development 113: 431-444.

Zwilling, E. 1956. Interaction between limb bud ectoderm and mesoderm in the chick embryo. II-Experimental limb duplication. J. Exp. Zool. 132: 173-186.

Zwilling, E. 1961. Limb morphogenesis. Adv. Morphogenet. 1: $301-330$. 


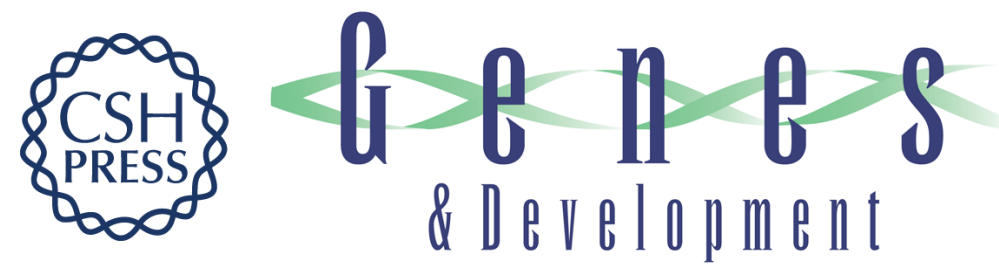

\section{The apical ectodermal ridge regulates Hox-7 and Hox-8 gene expression in developing chick limb buds.}

B Robert, G Lyons, B K Simandl, et al.

Genes Dev. 1991, 5:

Access the most recent version at doi:10.1101/gad.5.12b.2363

References This article cites 46 articles, 12 of which can be accessed free at:

http://genesdev.cshlp.org/content/5/12b/2363.full.html\#ref-list-1

License

Email Alerting

Service

Receive free email alerts when new articles cite this article - sign up in the box at the top right corner of the article or click here.

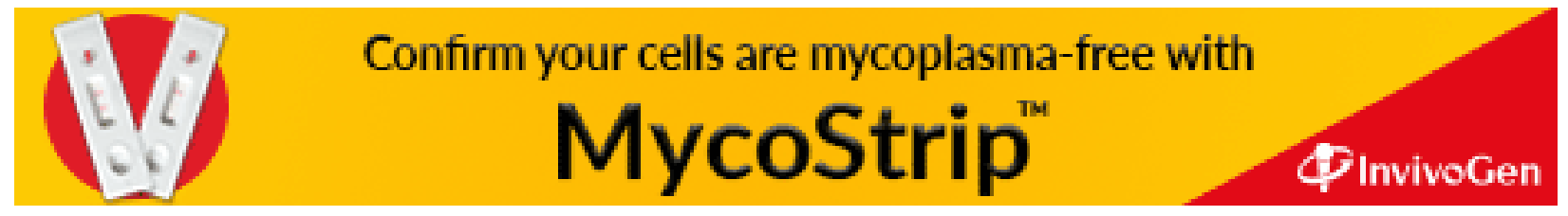

